\title{
PENGUASAAN LAYANAN KONTEN ENTREPRENUERSHIP MELALUI MANAJEMEN DIRI DI SMK MAHADHIKA 1 JAKARTA TIMUR
}

\author{
Djoni Aminudin $^{1)}$, Anggia Evitarini2), Dewi Purwaningsih ${ }^{3)}$ \\ Program Studi Bimbingan dan Konseling, Fakultas Ilmu Pendidikan dan Pengetahuan Sosial, \\ Universitas Indraprasta PGRI
}

\begin{abstract}
Abstrak
Tujuan pengabdian masyarakat ini yakni memberikan layanan penguasaan konten tentang membangun mindset enterpreunership para siswa agar mampu berfikir mandiri dan kreatif melalui wawasan manajemen diri untuk para peserta diantaranya tujuan dan manfaat manajemen diri, mengenai kepercayaan diri, kreativitas, dan manajemen waktu. Metode pelaksanaan dengan Observasi langsung dan workshop yaitu: pengabdi langsung datang ke lokasi pengabdiaan untuk memperoleh data kemudian memberikan materi entrepreneurship dan manajemen diri. Simpulan pengabdian masyarakat ini didapatkan para siswa SMK Mahadhika 1 ditemukan masih banyak yang berorientasi menjadi pegawai atau karyawan perusahaan, terutama bercita-cita menjadi seorang Pegawai Negeri Sipil. Hal ini disebabkan kurangnya informasi-informasi yang diberikan oleh personil $\mathrm{B} \& \mathrm{~K}$ yang terhambat tidak tersedianya jam khusus di dalam kelas. Hal ini menyebabkan kemampuan manajemen diri dan wawasan tentang entrepreneur para siswa SMK Mahadhika 1 masih sangat rendah. Personil B\&K masih berfokus yang bersifat mengentasan/mengatasi masalah. Pemberian layanan penguasaan konten efektif dalam meningkatkan pengetahuan para peserta terkait entreprenuership melalui manajemen dirinya.
\end{abstract}

Kata Kunci: Layanan Penguasaan Konten, Entreprenuership, Manajemen Diri

\begin{abstract}
The aim of community service is to provide content mastery service about building a mindset of entrepreneurship for students to be able to think independently and creatively through se; $f$ - management insights for participants including self-management goals and benefits, regarding self-confidence, creativity, and time management. The method of implementation used direct observation and workshops, namely: direct servants come to the service location to obtain data and then provide material entrepreneurship and self-management. The conclusion of this community service was found that the students of Mahadhika Vocational School still many had oriented to be employess or company employess especially aspiring to becooe a Civil Servants. This is due to the lack of information provided by $B \& K$ personnel which is hampered by the unavailability of specific hours in the classroom. So, It caused the ability of self management and insight about entrepreneurship of students of SMK Mahadhika 1 was stil very low. $B \& K$ personnels were stil focused on overcoming problems. Providing content mastery services was effective in increasing the knowledge of participants regarding entrepreneurship through sel-management.
\end{abstract}

Keywords: content mastery service, entreprenuership, and self-management

Correspondence author: Djoni Aminudin, aminudin1183@gmail.com, Jakarta, Indonesia 


\section{PENDAHULUAN}

Masalah yang sering dihadapi dan paling mendesak di dalam pendidikan itu di antaranya adalah kondisi para lulusannya. Yang dimaksud disini adalah para lulusan masih bingung kerja apa, bingung kuliah dimana, bingung usaha apa, dan lain-lain. Khususnya mengenai kurangnya keberanian dalam berwirausaha (enterpreuner). Siswa SMK pada dasarnya belum memiliki motivasi untuk berwirausaha. Sebagian besar lulusan khususnya SMK lebih sebagai pencari kerja dari pada pencipta lapangan pekerjaan. Jika melihat data yang ada, informasinya hampir Negara maju standardnya itu memiliki (penduduk) entrepreneur di atas 14 persen, sementara di kita, angkanya masih 3,1 persen. (kompas.com/2018/04/05). Jika temuan di lapangan tidak sedikit para siswa di SMK Mahadhika 1 Jakarta ingin menjadi seorang pekerja di sebuah perusahaan atau bermental pegawai daripada menjadi seorang wirausaha. Hal ini kurangnya motivasi wirausaha. Secara pengertian wirausaha (entreprenuership) adalah orang yang memiliki keberanian untuk melakukan usaha dengan tangannya sendiri, berani untuk menanggung resiko dan memiliki dedikasi untuk menjalankan bisnis hingga berhasil. Untuk mencapai keberhasilan ini. menurut David MeClelland diperlukan orang yang mempunyai " $n$, $A c h$ " (need for achievement atau kebutuhan akan prestasi) yang tinggi (Oswari, 2005).

Faktor yang berkaitan erat dengan motivasi berwirausaha adalah manajemen diri. Manajemen diri sangat diperlukan oleh siswa karena ia cenderung tertarik melakukan halhal yang dianggap menyenangkan dan menimbulkan kepuasan bagi dirinya sendiri. Secara pengertian Manajemen diri adalah suatu alat untuk menyalurkan keinginan dalam memenuhi kebutuhan kompetensi seseorang yang mempengaruhi keberhasilan seseorang dalam menjalani proses pendidikannya (Amir, 2016). Siswa yang memiliki manajemen diri tinggi akan mampu mengatur diri sendiri dan menentukan prioritas tujuan dengan menggunakan waktu se-efektif dan se-efisien mungkin melakukan proses perubahan untuk menciptakan kesejahteraan. Menanamkan mental Entreprenuership merupakan hal yang sangat penting, karena salah satu pendorong meningkatkan perekonomian di suatu Negara.

Beberapa faktor yang sudah di utarakan, maka tujuan pengabdian kepada masyarakat ini adalah agar para siswa khususnya SMK Mahadhika 1 Jakarta memiliki wawasan dan mindset manajemen diri, sehingga memiliki dan berani melakukan usaha terutama di bidang yang dikuasainya masing-masing.

\section{METODE PELAKSANAAN}

\section{Metode dan Prosedur Pelaksanaan Abdimas}

Metode yang akan dilakukan dalam kegiatan ini adalah melalui beberapa tahap:

1. Observasi langsung.

Observasi langsung yaitu: pengabdi langsung datang ke lokasi pengabdiaan untuk memperoleh data. Hal ini kami lakukan pada saat menjelang maupun saat kegiatan berlangsung. Observasi berguna untuk mengetahui kondisi para peserta didik di SMK Mahardhika 1 Ciracas Jakarta Timur terkait harapan atau perencanaan kariernya, serta menentukan materi apa yang diperlukan dalam memberikan pemahaman dari entrepreneurship. Observasi sangat penting untuk mewujudkan kesuksesan kegiatan pengabdiaan masyarakat itu sendiri. 
2. Workshop

Memberikan Penguasaan Konten terkait materi yang berkaitan dengan entrepreneurship dan konsep wawasan Manajemen diri kepada para peserta didik di SMK Mahardhika 1 berikut penerapannya agar mempunyai mindset entrepreneurship melalui manajemen diri:

a. Tim abdimas mempersiapkan kesiapan peserta melalui kegiatan ice breaking

b. Setelah siap, pemateri menyampaikan materi pertama yakni tentang enterprenuership (wirausaha) yang disampaikan oleh Dewi Purwaningsih., S.E.M.M.

c. Dilanjutkan materi tentang manajemen diri yang disampaikan oleh Djoni Aminudin, M.Pd.

\section{Peserta dan Pembimbing Kegiatan}

1. Peserta Kegiatan

Peserta kegiatan pengabdiaan masyarakat ini adalah para peserta didik di SMK Mahardhika 1 Ciracas, Jakarta Timur yakni siswa kelas X.AK-1 dan X.AK-2 yang keseluruhan berjumlah 66 orang siswa. (daftar siswa terlampir)

2. Pembimbing Kegiatan

Pembimbing kegiatan ini adalah dosen yang mengampu mata kuliah kewirausahaan serta dosen B\&K Karier serta yang pernah atau memiliki berbagai usaha dan mampu pada bidangnya. Berikut tabel 3.1 mengenai pembimbing kegiatan.

Tabel 3.1. Daftar Pembimbing Kegiatan:

\begin{tabular}{|l|l|l|}
\hline No. & \multicolumn{1}{|c|}{ Kegiatan } & \multicolumn{1}{c|}{ Pembimbing } \\
\hline 1. & Proposal dan Sosialisasi & $\begin{array}{l}\text { Anggia Evitarini, M.Pd. \& } \\
\text { Dewi Purwaningsih, S.E. M.M. }\end{array}$ \\
\hline 2. & Materi & $\begin{array}{l}\text { Dewi Purwaningsih, S.E.,M.M \& } \\
\text { Djoni Aminudin, M.Pd. }\end{array}$ \\
\hline 3. & Pelaksanaan Demonstrasi & Anggia Evitarini, M.Pd. \\
\hline 4. & Evaluasi dan Laporan & $\begin{array}{l}\text { Djoni Aminudin, M.Pd. } \\
\text { Anggia Evitarini, M.Pd. } \\
\text { Dewi Purwaningsih, S.E.,M.M }\end{array}$ \\
\hline 5. & Dokumentasi & $\begin{array}{l}\text { Hana Nurrohma Amatulloh } \\
\text { (Mahasiswa) }\end{array}$ \\
\hline
\end{tabular}

\section{Langkah - langkah Kegiatan}

Pelaksanaan kegiatan ini dilakukan dalam tiga tahap, yaitu : tahap persiapan, pelaksanaan, dan evaluasi. Tahap pertama adalah tahap persiapan. Pada tahap ini, tim melakukan survey pendahuluan dan wawancara kepada guru dan para peserta didik di SMK Mahardhika 1. Tahap ini guna untuk mencari kebutuhan yang diperlukan didalam lingkungan sekolah.

Tahap kedua yaitu: tahap pelaksanaan. Kegiatan ini dilakukan tim di awali dengan memberikan motivasi tujuan hidup termasuk ice breaking. Kemudian memberikan layanan penguasaan konten kepada peserta didik mengenai materi dalam hal pengembangan manajemen diri, implikasinya serta berdiskusi bagaimana cara mengembangkan mindset entrepreneur. Setelah pemberian layanan, berikutnya yaitu: memberikan kesempatan para peserta didik untuk berlatih mensimulasikan materi yang 
telah diterima di dalam ruangan dan memberikan kesempatan tanya jawab seputar materi tersebut.

Tahap yang terakhir adalah tahapan evaluasi. Evaluasi kegiatan ini dilakukan terhadap proses kegiatan. Evaluasi proses berkaitan dengan kehadiran peserta, semangat, dan antusias peserta mengikuti kegiatan dan kerja sama yang terjalin selama proses pelaksanaan, serta tingkat pemahaman para siswa dan siswi. Evaluasi proses dilakukan selama kegiatan berlangsung. Skema kegiatan pengabdian masyarakat disajikan dalam diagram berikut :

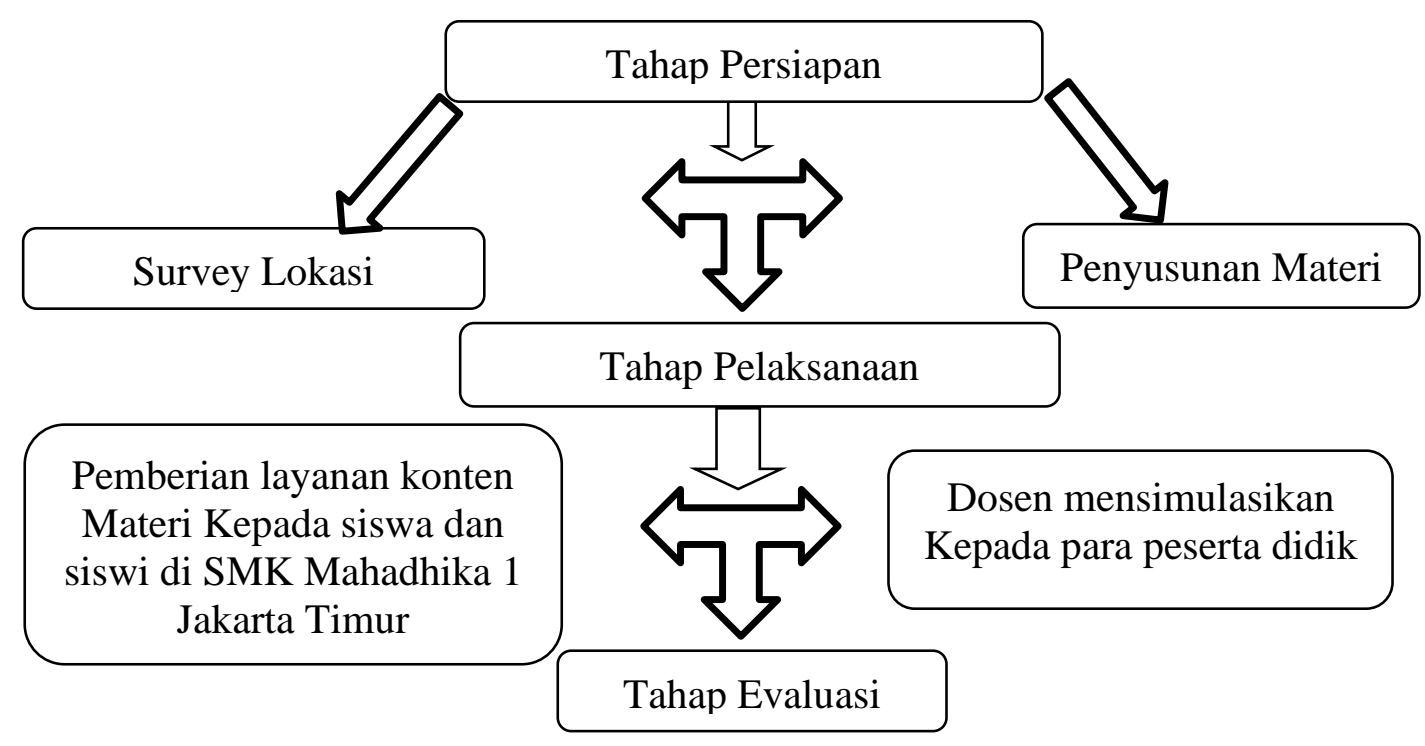

Gambar 1 Diagram Alur Program Kegiatan Pengabdian Masyarakat

\section{HASIL DAN PEMBAHASAN}

Kegiatan pengabdian kepada masyarakat di SMK Mahadhika 1 Jakarta Timur, mengenai Layanan Penguasaan Konten Entreprenuership melalui Manajemen Diri siswa. Hasilnya sebagai berikut:

1. Layanan Penguasaan Konten efektif dalam meningkatkan wawasan atau pengetahuan para siswa di SMK Mahadhika 1 Jakarta Timur.

2. Meningkatnya pengetahuan atau wawasan para peserta tentang entreprenuership beserta faktor pendukung dan penghambatnya.

3. Meningkatnya pengetahuan tentang konsep manajemen diri dan mengetahui cara penerapkannya dalam kehidupan yang efektif.

Masalah yang sering dihadapi dan paling mendesak di dalam pendidikan itu diantaranya adalah kondisi para lulusannya. Yang dimaksud disini adalah para lulusan masih bingung kerja apa, bingung kuliah dimana, bingung usaha apa, dan lainlain. Khususnya mengenai kurangnya keberanian dalam berwirausaha (enterpreuner). Jika melihat data yang ada, informasinya hampir Negara maju standardnya itu memiliki (penduduk) entrepreneur di atas 14 persen, sementara di kita, angkanya masih 3,1 persen. (kompas.com/2018/04/05).

Kenyataan itu sangatlah memprihatinkan khususnya bagi dunia pendidikan kita, hal ini dapat disebabkan karena pada umumnya pendidikan di sekolah selama ini masih fokus 
mempersiapkn siswa menjadi seorang karyawan perusahaan, belum berorientasi bagaimana menyiapkn siswa bisa dan berani berwirausaha. Kondisi ini tidak akan menumbuh kembangkan aspek kemampuan dan aktivitas peserta didik

Menanamkan mental Entreprenuership merupakan hal yang sangat penting, karena salah satu pendorong meningkatkan perekonomian di suatu negara adalah dilihat dari jumlah entreprenuer yang ada, banyak diantara para siswa khususnya, tidak memiliki mental menjadi seorang pengusaha (memiliki usaha sendiri), untuk itulah pentingnya mindset yang harus ditanamkan sejak dini. Mereka perlu juga diajarkan kemandirian, berani mengambil resiko dan berlatih mengambil keputusan sendiri dan semua itu harus dipupuk dari sekarang.

Menanamkan mental atau mindset tersebut melalui meningkatkan kemampuan manajemen diri mereka, seperti meningkatkan kemampuan manejemen waktu, kreativitas, dan kepercayaan diri. Karenanya sebuah sekolah perlu membekali jiwa enterprenuer tersebut sejak dini. Jadi ketika mereka lulus dari sekolah, mereka sudah siap bersaing di dunia luar.

Berikut beberapa dokumentasi hasil kegiatan pengabdian kepada masyarakat kami:
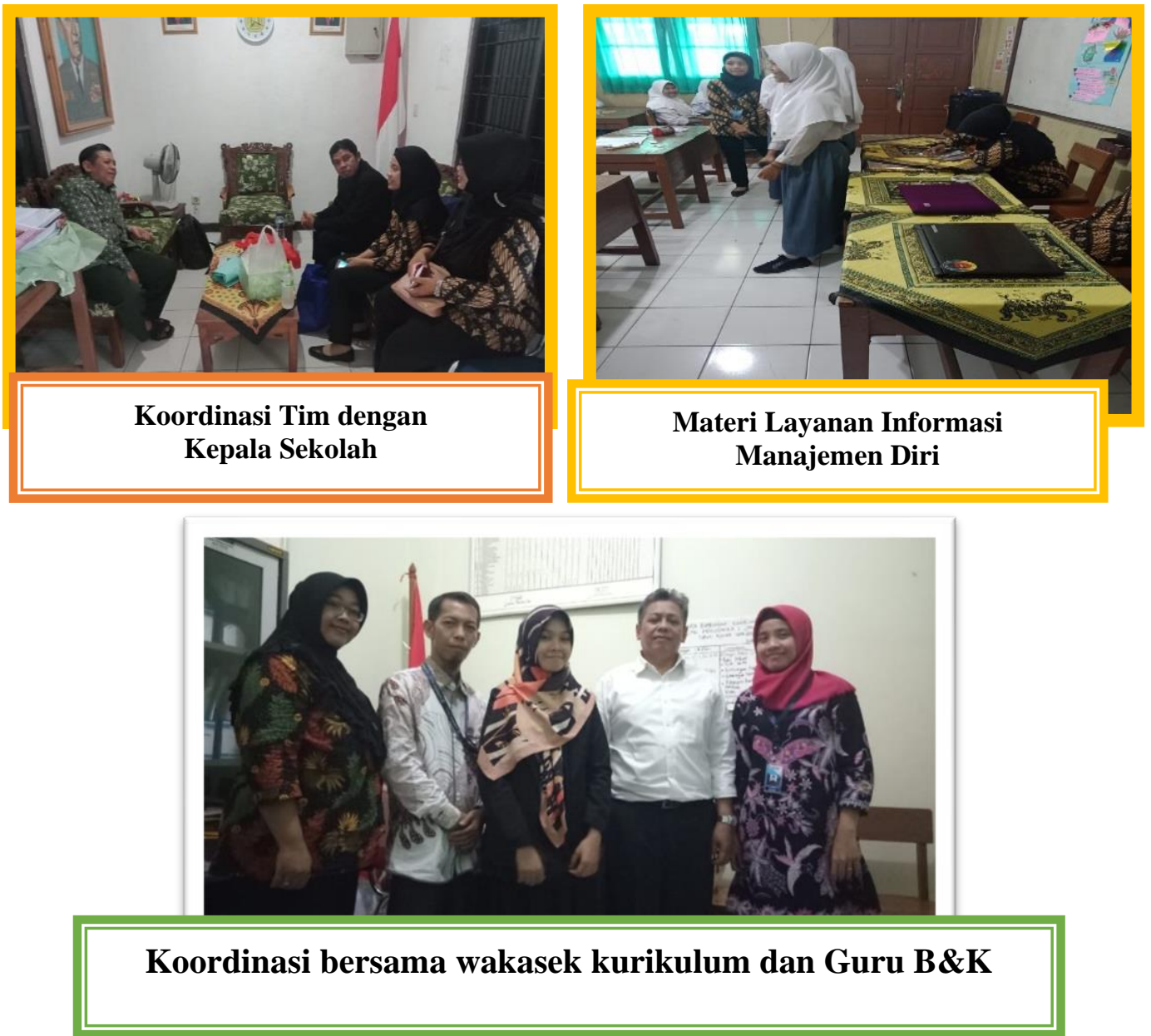

Gambar 2. Dokumentasi Kegiatan 


\section{SIMPULAN}

Para siswa SMK Mahadhika 1 ditemukan masih banyak yang berorientasi menjadi pegawai atau karyawan perusahaan, terutama bercita-cita menjadi seorang PNS. Hal ini disebabkan kurangnya informasi-informasi yang diberikan oleh personil B\&K yang terhambat tidak tersedianya jam khusus di dalam kelas. Hal ini menyebabkan kemampuan manajemen diri dan wawasan tentang entrepreneur para siswa SMK Mahadhika 1 masih sangat rendah. Personil B\&K masih berfokus yang bersifat mengentasan/mengatasi masalah.

Pemberian Layanan Penguasaan Konten efektif dalam meningkatkan pengetahuan para peserta terkait entreprenuership melalui manajemen dirinya.

Menanamkan mental Entreprenuership merupakan hal yang sangat penting, karena salah satu pendorong meningkatkan perekonomian di suatu negara adalah dilihat dari jumlah enterprenuer yang ada, banyak diantara para siswa khususnya, tidak memiliki mental menjadi seorang pengusaha (memiliki usaha sendiri), untuk itulah pentingnya mindset yang harus ditanamkan sejak dini. Mereka perlu juga diajarkan kemandirian, berani mengambil resiko dan berlatih mengambil keputusan sendiri dan semua itu harus dipupuk dari sekarang.

\section{DAFTAR PUSTAKA}

Amir, H. (2016). Korelasi pengaruh faktor efikasi diri dan manajemen diri terhadap motivasi berprestasi pada mahasiswa pendidikan kimia Unversitas Bengkulu. Manajer Pendidikan, 10(4).

Kompas.com.(2018).https://nasional.kompas.com/read/2018/04/05/

Oswari, T. (2005). Membangun Jiwa Kewirausahaan (Entrepreneurship) Menjadi Mahasiswa Pengusaha (Entrepreneur Student) Sebagai Modal Untuk Menjadi Pelaku Usaha Baru. In Proceeding, Seminar Nasional PESAT 2005. Universitas Gunadarma. 